\title{
Role of early postoperative ultrasonography in prediction of AV fistula failure in hemodialysis patients
}

\author{
Mohamed Kamel Abd-Elmageed ${ }^{1}$, Basma Fathy Elsayed ${ }^{2 *}$ and Mohamed Ramadan Elkholy ${ }^{1}$
}

\begin{abstract}
Background: Doppler ultrasonography (US) is the main imaging modality of hemodialysis AV fistula as it is safe non-invasive accurate modality. This study is to measure the arteriovenous (AV) fistula blood flow during early postoperative period (7-14 days) and assess its predictive role in AV fistula failure in hemodialysis patients. Color Doppler ultrasonography (CDU) was used to estimate the blood flow in the AV fistula of 100 patients at (7-14 days) after the fistula creation. The performance of fistula blood flow during early postoperative periods for predicting fistula failure was evaluated, and optimal cutoff value was determined.

Results: During the follow-up period (6 months), we classified the fistulas as 82 mature, and 18 failed. The blood flow was considerably lower in the failure group than that in the mature group at the early postoperative period $(P$ value $=0.001$ ). The areas under the curves (AUC) were 0.952 , and the cutoff value was $200.5 \mathrm{ml} / \mathrm{min}$. The sensitivity of CDU in prediction of fistula failure is $99 \%$ with negative predictive value $94 \%$ and accuracy $97 \%$, and with specificity $89 \%$ and positive predictive value $98 \%$.
\end{abstract}

Conclusion: Measuring blood flow of the AV fistula at the early postoperative period probably has a predictive role in the AV fistula failure. There is risk of failure if the blood flow less than $200 \mathrm{ml} / \mathrm{min}$ at (day 7-14)

Keywords: Arteriovenous fistula, Color Doppler ultrasonography, Fistula blood flow, Fistula failure

\section{Background}

Chronic renal failure (CRF) is characterized by impaired renal function, which is progressive and irreversible [1]. In recent years, the improvement in the diagnosis and treatment of kidney diseases has led to an increase in the number of patients who need hemodialysis. The annual increase in dialysis patients has been around $8 \%$ [2].

The long-term survival of the patients on hemodialysis is dependent on the adequacy of dialysis via an appropriately placed vascular access [3]. Although arteriovenous fistula is the preferred vascular access for hemodialysis, there is still a high rate of failure to mature in clinical practice.

\footnotetext{
* Correspondence: Basmafathy99@gmail.com

${ }^{2}$ Department of Radiodiagnosis, Shebin Elkom Teaching Hospital, Shibin Al Kawm, Menoufia, Egypt

Full list of author information is available at the end of the article
}

Recent data have demonstrated the importance of timely intervention for salvaging early fistula failure. However, clinically, it could be more than 3 to 4 months before an AV fistula is declared immature. Therefore, well-defined criteria applied early after fistula creation to help identify fistulas that are likely to fail would be extremely useful.

To further increase the use of AVFs, especially in the co-morbid patient, a thorough preoperative evaluation with colour Doppler ultrasound (CDU) and mapping of the arterial and venous vascular system allows the placement of an AVF in a higher proportion of patients and to achieve a better cumulative patency rate of fistulas [4].

After creation of access, periodic monitoring is recommended, since early detection of access dysfunction and subsequent intervention may help to reduce the rate of access failure. Doppler ultrasound is the main imaging

\section{Springer Open}

(๑) The Author(s). 2020 Open Access This article is licensed under a Creative Commons Attribution 4.0 International License, which permits use, sharing, adaptation, distribution and reproduction in any medium or format, as long as you give appropriate credit to the original author(s) and the source, provide a link to the Creative Commons licence, and indicate if changes were made. The images or other third party material in this article are included in the article's Creative Commons licence, unless indicated otherwise in a credit line to the material. If material is not included in the article's Creative Commons licence and your intended use is not permitted by statutory regulation or exceeds the permitted use, you will need to obtain permission directly from the copyright holder. To view a copy of this licence, visit http://creativecommons.org/licenses/by/4.0/. 
modality for assessment of dialysis access circuits because they are superficial and allows good evaluation by CDU [5]. It cannot just give information on the morphological criteria but it also evaluates the inflow and outflow flows; ultrasound is non-invasive modality with no ionizing radiations or iodinated contrast media, and it is a low-cost and accessible imaging modality [6].

Immediately after fistula creation, blood flow increases rapidly, reaching a maximum within 4 to 12 weeks, and between $40 \%$ to $60 \%$ of the total increase in blood flow occurs within $24 \mathrm{~h}$ after creation of the fistula [7]. On the basis of these considerations, we hypothesized that the measuring of blood flow in an arteriovenous fistula by CDU during early postoperative period (day 7-14) might be predictive of failure of a fistula to mature.

\section{Methods}

After approval of the Local Ethical Committee and obtaining written consents from all patients to participate in the study, this study was done in the Radiodiagnosis Department from March 2018 to February 2019. This study was carried on 100 patients with ESRD coming for AVF creation.

\section{Inclusion criteria:}

1. Both male and female patients diagnosed as ESRD and required a hemodialysis AVF for the 1st time.

2. Patients who had malfunctioning AVF and required new creation of fistula at the other limb.

3. Patients who attended follow-up postoperative (day 7-14) and for dialysis sessions.

4. Presence of temporary catheter for dialysis was not the exclusion criteria.

\section{Exclusion criteria:}

1. Previous fistula formation in the same upper limb.

2. Patients with poor vascularity (such as obvious vessel wall calcification and small caliber).

3. Any fistula failure within 1 week is considered surgical failure and excluded.

\section{Equipment and supplies:}

1) Standard supplies for ultrasonic exam: acoustic coupling gel, gloves, and skin wipes.

2) Tourniquet for measuring vein size.

3) Pillow(s) or foam pad to position the patient comfortably.

4) Transducers used in the study are curved and linear.

5) B mode and Doppler mode ultrasound scanner (general electric model logiq 7 version) which includes display of both two-dimensional structure and motion in real-time.

All patients were subjected to:

1) Careful history taking (age, sex, primary renal disease) and physical examination.

2) Preoperative vascular mapping:

a. Gray scale B mode to get the morphological criteria of the vessels (the diameter of the cephalic $\mathrm{V}$ at the wrist, radial $\mathrm{A}$, and the brachial A $5 \mathrm{~cm}$ above the elbow).

b. Color Doppler imaging to assess the hemodynamics including Peak Systolic Velocity (PSV) of the radial and brachial arteries.

3) Postoperative:

i. day 7-14:

1. Gray scale B mode to check the feeding artery, the anastomosis, and the draining vein to exclude stenosis or other complications

2. Color coded Doppler imaging to estimate the blood flow at the fistula site.

ii. $4-6$ weeks:

1. Clinical evaluation to decide whether it is suitable for dialysis (nephrology and vascular team were involved).

2. Physical exercises as squeezing and releasing a stress ball were advised to be done by patients to enhance fistula maturation. The first cannulation of the fistula was done according to fistula maturation and the need for dialysis initiation, and it was performed at least 4 weeks after fistula creation.

3. Experienced dialysis nurses evaluated the fistula before the first canulation to assess if it was suitable for dialysis initiation or not. Fistula was suitable for cannulation if detecting an easily palpable superficial vein (straight $<6 \mathrm{~cm}$ long) and thrill on palpation.

4. Clinical outcome was known for all included patients (regular follow-up and hemodialysis unit visits).

5. Arteriovenous fistula that could support mean pump controlled blood flow of $377 \mathrm{ml} / \mathrm{min}$ in at least 3 dialysis sessions was considered mature, and maturation was gratified at any time in the first 6 months after fistula construction.

6. We considered mature fistula in our study is the case with unassisted maturation, i.e., fistula that 
met the criteria of maturation before any surgical correction.

7. Failure of maturation is the cases in which the fistula never could been used as a dialysis circuit or failed to meet the criteria of maturation. Assisted maturation (functioning fistula after surgical correction was considered failed in our study).

8. Fistulas that were removed because of infection and needed an intervention or surgical modification, including thrombosis and stenosis, were considered failures too.

\section{Technique of examination:}

1. The patient arm was abducted at nearly $45^{\circ}$ from his body, in a comfortable position.

2. Care was taken to ensure that the probe was adequately covered by coupling gel with gentle compression so as not to compress the superficial vein.

3. All vessels were examined in both transverse and longitudinal planes.

4. Preoperatively, the vessels were examined by B mode to determine the compressibility and the patency of the veins and their diameters. The diameter was determined in a transverse plane from inner edge to inner edge. Then, color images were obtained to assess the direction of blood flow and to confirm the data recorded from B mode examination. Lastly, Doppler studies were performed, using 7-12 MHZ probe in transverse and longitudinal planes with Doppler angle always between $\left(45-60^{\circ}\right)$, with the angle kept relatively constant for each vessel throughout the study.

5. Peak systolic velocity (PSV) $(\mathrm{cm} / \mathrm{sec})$ in brachial and radial arteries was measured. The sample volume size (SV) was adequate to include the whole luminal cross section of the vessel.

6. Postoperatively, CDU examination of a dialysis fistula was performed prior to dialysis, to avoid examination related infection or post procedural bleeding from the puncture site.

7. The fistulae blood flow measurements were done at the same location which was at the anastomosis, without compression.

8. When measuring the blood flow at the anastomosis, the Doppler angle was set between $45^{\circ}$ and $60^{\circ}$ to limit one potential aspect of measurement variability, and the sample volume (SV) was oriented parallel to the direction of blood flow, positioned at the center of the vessel but the amplitude adjusted to allow sampling of $70 \%$ of the vessel lumen. Pulse repetition frequency (PRF) was adjusted to eliminate artifacts.
9. Fistulae blood flow for each fistula was measured three times repetitively, and the mean value was documented.

10. The flow volume formula is blood flow (milliliters per minute) $=$ time-averaged mean velocity (meters per seconds) $\times$ cross-sectional area (square millimeters).

11. This was calculated electronically by the machine.

\section{Signs of maturity of the fistula by Doppler examination:}

1. Flow volume at the fistula site $>377 \mathrm{ml} / \mathrm{min}$ in at least 3 dialysis sessions.

2. No complications are detected.

\section{Statistical analysis}

Data were collected, tabulated, and statistically analyzed using an IBM personal computer with the Statistical Package of Social Science (SPSS) version 22 (SPSS, Inc, Chicago, IL, USA) where the following statistics were applied:

1. Descriptive statistics: mean $(\bar{X})$, standard deviation (SD) was used to describe the quantitative data as in (age, BMI, cephalic vein diameter, radial artery diameter and PSV, brachial artery diameter and PSV, early postoperative blood flow, and late postoperative blood flow).

Qualitative data were presented in the form of numbers and percentages as in causes of renal disease, mature, and failed fistula, and causes of fistula failure, gender, diabetes mellitus, and type of anastomosis.

Analytical statistics used to find out the possible association between studied factors and the targeted disease. The used tests of significance included:

"Chi-squared test $\left(x^{2}\right)$ was used to study association between two qualitative variables like gender and diabetes mellitus.

Table 1 Causes of renal disease among studied group

\begin{tabular}{lll}
\hline Studied variables & \multicolumn{2}{l}{ Studied group } \\
\cline { 2 - 3 } & No. & $\%$ \\
\hline Causes of renal disease & & 47.0 \\
Chronic nephritis & 47 & 24.0 \\
Diabetic nephropathy & 24 & 13.0 \\
Hypertensive nephropathy & 13 & 8.00 \\
Polycystic kidney & 8 & 8.00 \\
Unknown & 8 & \\
\hline
\end{tabular}




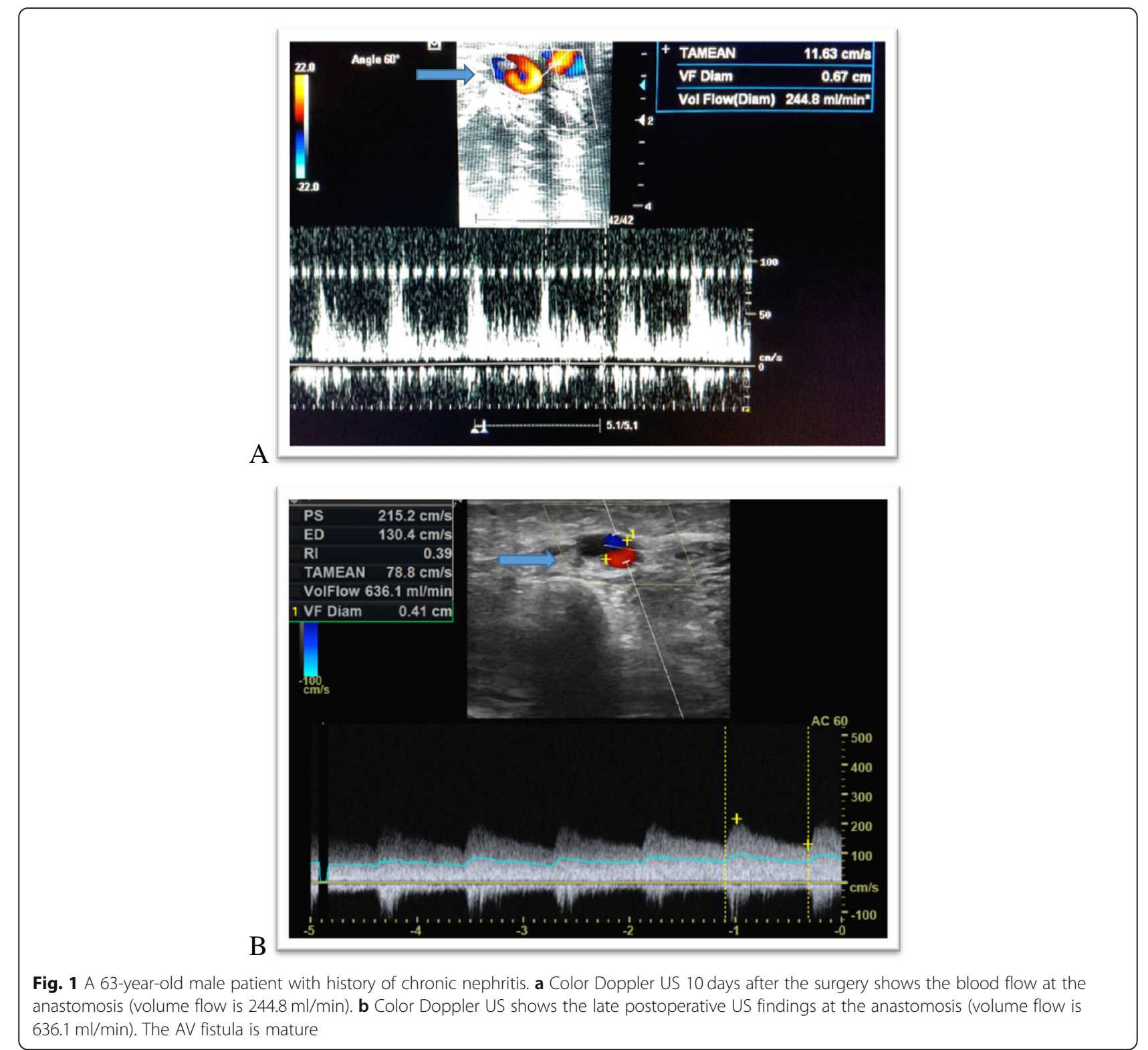

"Fischer's exact test for $2 \times 2$ tables when expected cell count of more than $25 \%$ of cases was less than 5 as in type of anastomosis.

"Student's $t$ test is a test of significance used for comparison between two groups having quantitative variables as age, BMI, cephalic vein diameter, radial artery diameter, and brachial artery diameter.

"Mann-Whitney test (nonparametric test) is a test of significance used for comparison between two groups not normally distributed having quantitative variables as radial artery PSV, brachial artery PSV, early postoperative blood flow, and late postoperative blood flow.

The ROC (reciver operating characteristic) curves: this procedure used in Tables 7 and 8 for detection of
Table 2 Outcome of AV fistula and cause of failure among studied group

\begin{tabular}{lll}
\hline Studied variables & \multicolumn{2}{l}{ Studied group } \\
\cline { 3 - 3 } & No. & $\%$ \\
\hline Fistula & 82 & 82.0 \\
$\quad$ Mature & 18 & 18.0 \\
$\quad$ Failed & & \\
Causes of failure & 9 & 50.0 \\
Failed to mature & 4 & 22.2 \\
Hematoma & 1 & 5.60 \\
Infection & 3 & 16.7 \\
Partial thrombosis & 1 & 5.60 \\
Total thrombosis & & \\
\hline
\end{tabular}


A
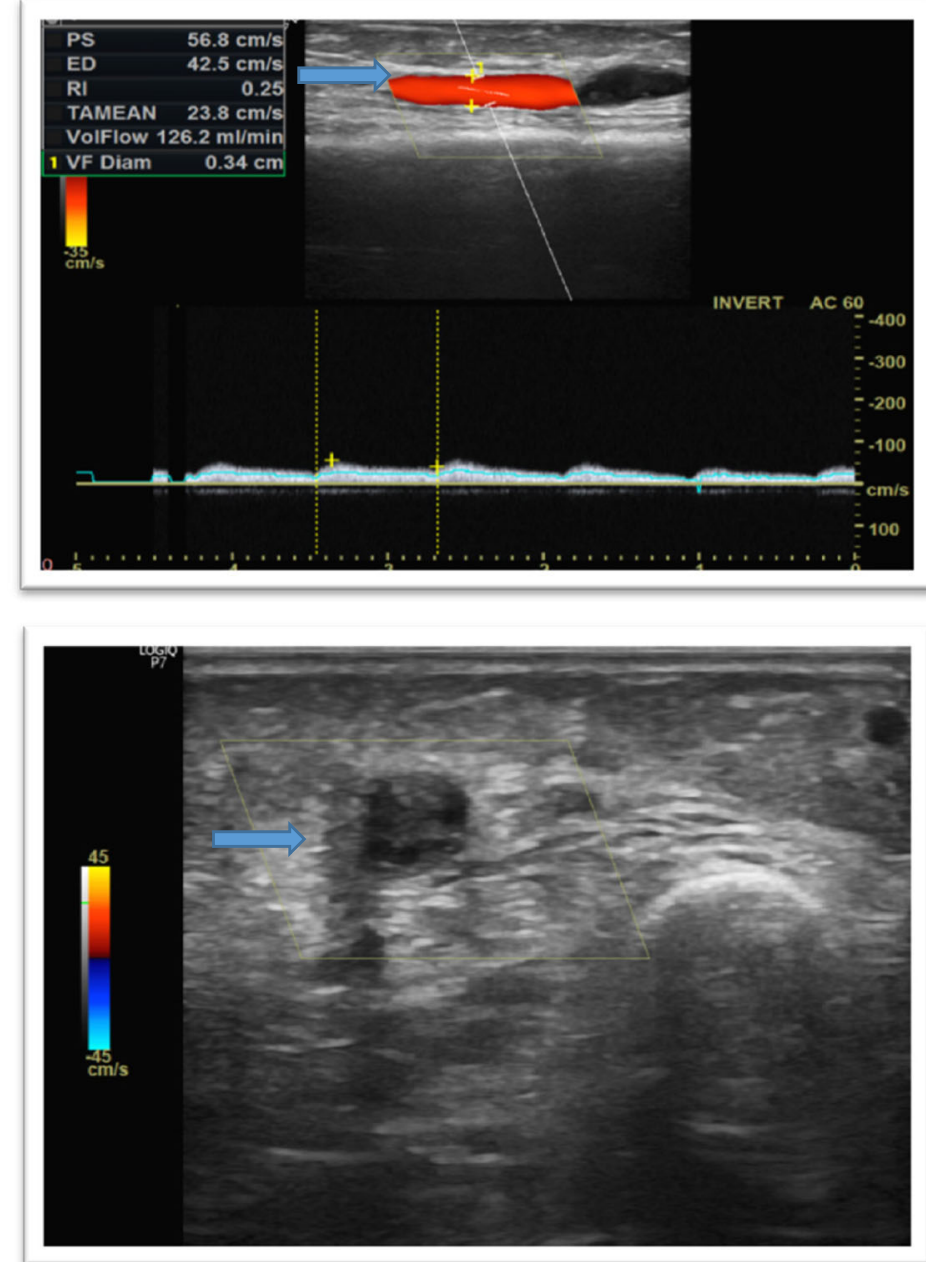

$\mathrm{B}$

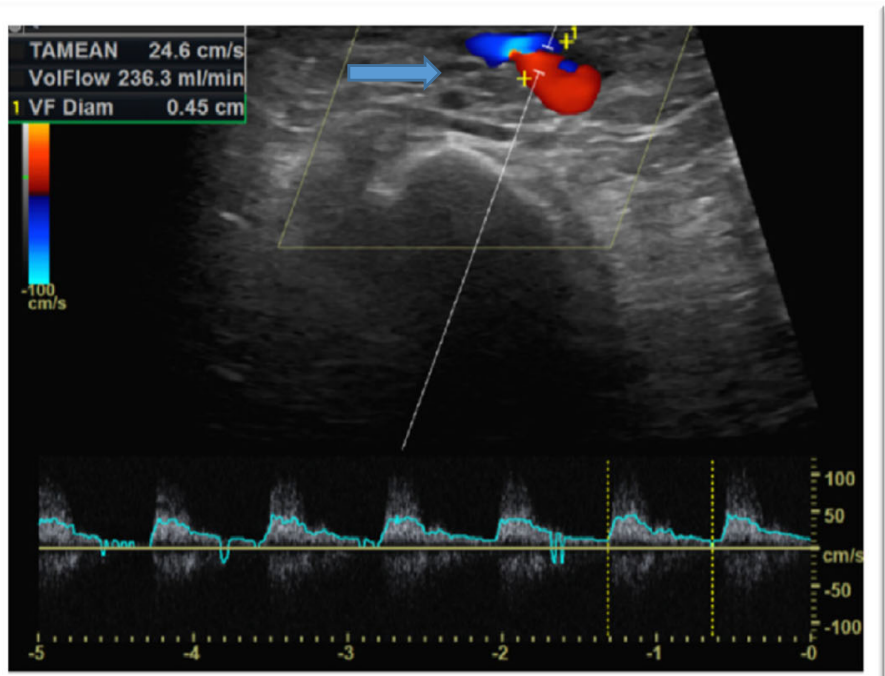

C

Fig. 2 A 67-year-old male patient with history of diabetic nephropathy. a Color Doppler US 8 days after the surgery shows the blood flow at the anastomosis (volume flow measurement is $126.2 \mathrm{ml} / \mathrm{min}$ ). b Color Doppler US demonstrates total thrombosis of the cephalic vein at the late postoperative period, and no color flow was detected. c Color Doppler US shows the late postoperative period volume flow measurement 236.3 $\mathrm{ml} / \mathrm{min}$, this fistula failed, and the cause of failure was total thrombosis of the cephalic vein 
sensitivity and specificity of fistula blood flow measured by sonography in early and late postoperative period in detection of AV fistula failure among the studied group.

Sensitivity, specificity, positive and negative predictive value, and diagnostic accuracy were calculated according to the following formulas:

- Sensitivity $=a /(a+c)$

- Specificity $=d /(b+d)$

- Accuracy $=(a+d) /(a+b+c+d)$

- Negative predictive value $=d /(c+d)$

- Positive predictive value $=a /(a+b)$

where $a$ is the true positive cases, $b$ is the false positive cases, $c$ is the false negative cases, and $d$ is the true negative cases.

$P$ value of $>0.05$ was considered statistically nonsignificant.

$P$ value of $<0.05$ was considered statistically significant.

$P$ value of $<0.001$ was considered statistically highly significant.

\section{Results}

The study included 100 patients with ESRD planning for AVF creation aged from 32 to 73 years, with the mean range of $59.8 \pm 8.10$ years. Males in the study group are $47(47 \%)$, and females are 53 (53\%). The mean BMI was $22.9 \pm 2.31$. Thirty-six percent of patients were diabetics, and $64 \%$ were non-diabetics.
Forty-seven percent of patients in the study have primary renal disease chronic nephritis, $24 \%$ have diabetic nephropathy, $13 \%$ with hypertensive nephropathy, $8 \%$ polycystic kidney, and $8 \%$ have unknown primary renal disease (Table 1) (Fig. 1).

In the preoperative mapping of the upper limb vessels, the mean diameter of cephalic vein is $2.32 \pm 0.24 \mathrm{~mm}$; radial artery mean diameter is $2.21 \pm 0.316 \mathrm{~mm}$; radial artery mean PSV is $52.1 \pm 16.7 \mathrm{~cm} / \mathrm{sec}$; brachial artery mean diameter is $4.32 \pm 0.456 \mathrm{~mm}$; and its mean PSV is $63.4 \pm 14.5 \mathrm{~cm} / \mathrm{sec}$.

During the follow-up period (6 months), $82 \mathrm{AV}$ fistulas were considered mature (82\%), and the cannulation was done at least 1 month after surgery; 18 AV fistulas (18\%) were considered failed at least 2 weeks after fistula construction. Causes of failure: it comprised 9 cases with immature fistulas (50\%) and could not support volume flow of $377 \mathrm{~mL} / \mathrm{min}$ for at least 3 dialysis sessions, 4 cases with hematoma (22.2\%), 3 cases with partial thrombosis (16.7), 1 case with total thrombosis (5.6\%), and 1 case with infection (5.6\%) (Table 2) (Fig. 2).

Highly significant relation between outcome of the fistula and age. Mean age of failure group was higher than the mature group, $68.3 \pm 3.08$ vs $58.0 \pm 7.67(P$ value $=$ 0.001). No significant relation between outcome of the fistula and BMI. Mean BMI of the failure group was 22.1 \pm 2.05 , and the mature group was $23.1 \pm 2.34$ ( $P$ value $=$ 0.093). No significant relation between the outcome of the fistula and gender. $33.3 \%$ of the failure group were males, and $66.7 \%$ were females, and $50 \%$ of the mature group were males, and 50\% were females ( $P$ value $=$ 0.200 ). The incidence of diabetes mellitus was higher in

Table 3 Relation between outcome of fistula and demographic data of the studied group

\begin{tabular}{|c|c|c|c|c|}
\hline \multirow[t]{2}{*}{ Studied variables } & \multicolumn{2}{|c|}{ Outcome of fistula } & \multirow[t]{2}{*}{ Test of sig. } & \multirow[t]{2}{*}{$P$ value } \\
\hline & Mature $(N=82)$ & Failed $(n=18)$ & & \\
\hline Age/years & & & $t$ test $=9.25$ & $0.001 * *$ \\
\hline Mean \pm SD & $58.0 \pm 7.67$ & $68.3 \pm 3.08$ & & \\
\hline Median & 59.0 & 69.0 & & \\
\hline Range & $32-71$ & $62-73$ & & \\
\hline BMI (Kg/m2) & & & $t$ test $=1.69$ & 0.093 \\
\hline Mean \pm SD & $23.1 \pm 2.34$ & $22.1 \pm 2.05$ & & \\
\hline Median & 23.0 & 22.8 & & \\
\hline Range & $18-28.4$ & $18.5-24.3$ & & \\
\hline Gender & No (\%) & No (\%) & $x_{2}$ & 0.200 \\
\hline Male & $41(50.0)$ & $6(33.3)$ & & \\
\hline Female & $41(50.0)$ & $12(66.7)$ & & \\
\hline Diabetes mellitus & No (\%) & No (\%) & X2 & $0.001 * *$ \\
\hline Yes & $23(28.0)$ & $13(72.2)$ & 12.5 & \\
\hline No & $59(72.0)$ & $5(27.8)$ & & \\
\hline
\end{tabular}

$X 2$ chi-squared test

**High significant 
the failure group (72\%) than in the mature group (28\%), and there was significant relation between outcome of the fistula and DM ( $P$ value $=0.001)$ (Table 3) $($ Fig. 3$)$.

Highly significant relation between outcome of the fistula and cephalic vein diameter $(P$ value $=0.001)$. Highly significant relation between outcome of the fistula and radial artery PSV $(P$ value $=0.001)$. High significant relation between outcome of the fistula and radial artery diameter $(P$ value $=0.001)$. High significant relation between outcome of the fistula and brachial artery PSV $(P$ value $=0.001)$. Highly significant relation between outcome of the fistula and brachial artery diameter $(P$ value $=$ 0.001) (Table 4) (Fig. 4).

Eighty-three percent of patients have their AV shunt surgery by end to side technique and $17 \%$ by end to end technique. There was no significant relation between outcome of the fistula and type of anastomosis; $20.7 \%$ of the mature group were end to end type, and $79.3 \%$ were end to side; $27.8 \%$ of the failure group were end to end, and $72.2 \%$ were end to side $(P$ value $=0.513)($ Table 5$)$ (Fig. 5).

In the early postoperative period (day7-14), the mean blood flow of failure group was $196.7 \pm 11.3$ vs $225.0 \pm$ 10.5 in the mature group. In the late postoperative period, the mean blood flow of the failure group was $271.2 \pm 28.8$ vs $567.1 \pm 142.0$ in the mature group (in at least 3 dialysis sessions).

The blood flow in the fistula in the failure group showed an increase of $38.2 \%$ at the period of follow-up, whereas increase of $88 \%$ in the mature group.

Highly significant relation between outcome of the fistula and early postoperative volume flow $(\mathrm{VF})(P$ value $=$

A
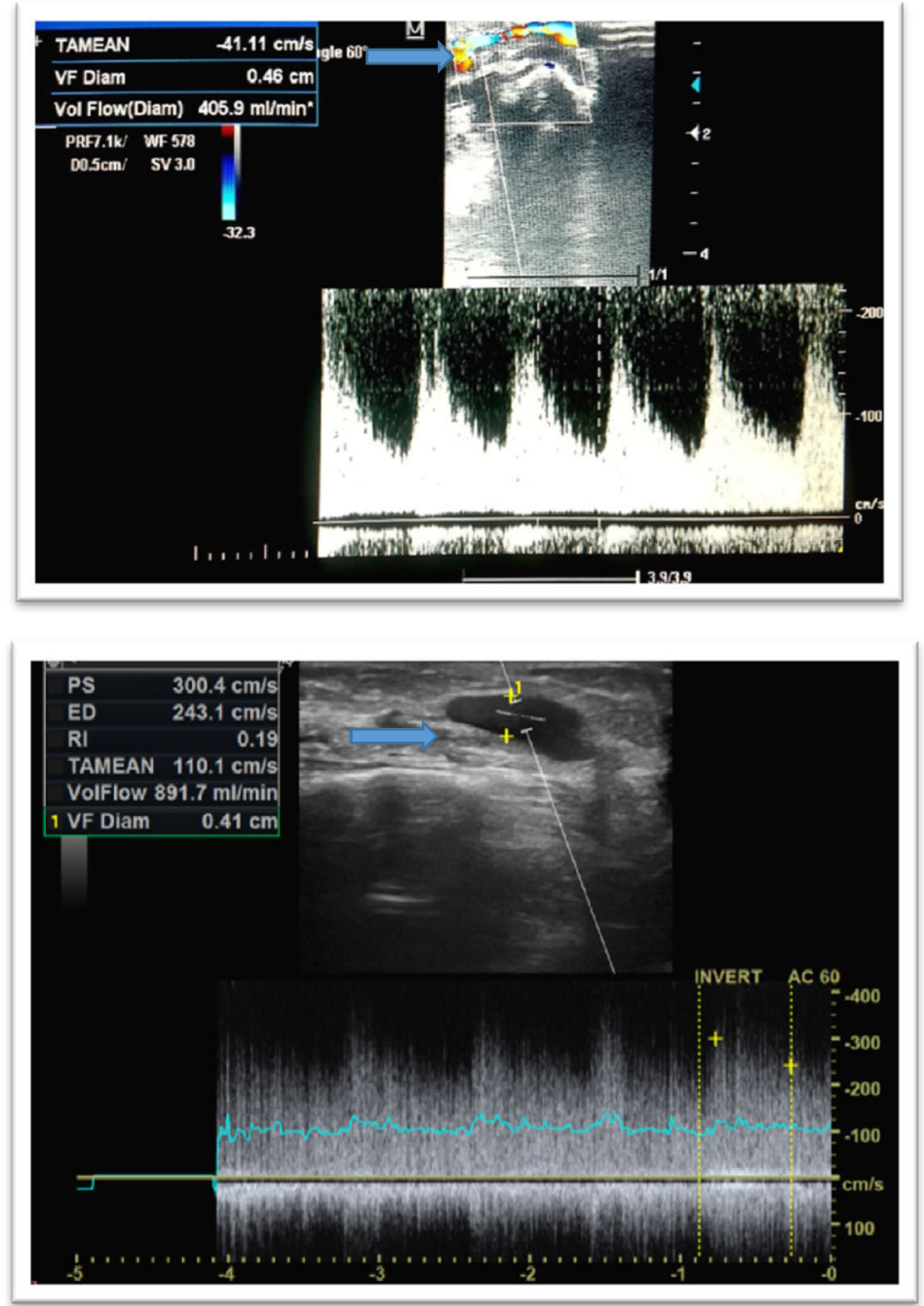

Fig. 3 A 51-year-old female patient with history of chronic nephritis. a Color Doppler US 12 days after the surgery shows blood flow at the anastomosis (volume flow is $405.9 \mathrm{ml} / \mathrm{min}$ ). b Color Doppler US shows late postoperative blood flow at the anastomosis (volume flow is $891.7 \mathrm{ml} /$ min). The AV fistula is mature 
Table 4 Relation between outcome of fistula and preoperative ultrasound findings

\begin{tabular}{|c|c|c|c|c|}
\hline \multirow[t]{2}{*}{ Studied variables } & \multicolumn{2}{|l|}{ Outcome of fistula } & \multirow[t]{2}{*}{ Test of sig. } & \multirow[t]{2}{*}{$P$ value } \\
\hline & Mature $(N=82)$ & Failed $(n=18)$ & & \\
\hline Cephalic vein diameter (mm) & & & $t$ test $=9.50$ & $0.001^{* *}$ \\
\hline Mean \pm SD & $2.39 \pm 0.19$ & $2.0 \pm 0.13$ & & \\
\hline Median & 2.40 & 2.0 & & \\
\hline Range & $2.0-2.8$ & $1.7-2.2$ & & \\
\hline Radial artery peak systolic velocity $\mathrm{cm} / \mathrm{sec}$ & & & $U=4.41$ & $0.001^{* *}$ \\
\hline Mean \pm SD & $68.1 \pm 11.1$ & $48.5 \pm 15.7$ & & \\
\hline Median & 64.5 & 43.0 & & \\
\hline Range & $54.0-88.0$ & $32.0-85.0$ & & \\
\hline Radial artery diameter (mm) & & & $t$ test $=11.2$ & $0.001^{* *}$ \\
\hline Mean \pm SD & $2.29 \pm 0.262$ & $1.78 \pm 0.150$ & & \\
\hline Median & 2.30 & 1.75 & & \\
\hline Range & $1.8-2.7$ & $1.6-2.1$ & & \\
\hline Brachial artery peak systolic velocity $\mathrm{cm} / \mathrm{sec}$ & & & $U=6.04$ & $0.001 * *$ \\
\hline Mean \pm SD & $77.0 \pm 10.9$ & $60.4 \pm 13.5$ & & \\
\hline Median & 74.5 & 56.0 & & \\
\hline Range & $60.0-93.0$ & 43.0-92.0 & & \\
\hline Brachial artery diameter (mm) & & & $t$ test $=2.61$ & $0.011 *$ \\
\hline Mean \pm SD & $4.56 \pm 0.52$ & $4.26 \pm 0.425$ & & \\
\hline Median & 4.75 & 4.2 & & \\
\hline Range & $3.0-5.2$ & $3.4-5.6$ & & \\
\hline
\end{tabular}

U Mann-Whitney test

**High significant, *significant

0.001). Highly significant relation between outcome of the fistula and late postoperative $\operatorname{VF}(P$ value $=0.001)$ (Table 6).

The cutoff value in early postoperative period (7-14 days) was $200.5 \mathrm{ml} / \mathrm{min}$, and the sensitivity of blood flow measurement in early postoperative period for prediction of fistula failure is $99 \%$ with negative predictive value $94 \%$ and accuracy $97 \%$, specificity $89 \%$, and positive predictive value $98 \%$ (Table 7).

The cutoff value in late postoperative period (for at least 3 dialysis sessions) was $377 \mathrm{ml} / \mathrm{min}$, and the sensitivity of blood flow measurement in late postoperative period for prediction of fistula failure is $99 \%$ with negative predictive value 95\% and accuracy 99\%, specificity $100 \%$, and positive predictive value $100 \%$ (Table 8 ).

\section{Discussion}

Chronic renal failure (CRF) is a progressive and permanent deterioration in renal function [1]. Number of patients who need hemodialysis has increased due to the advance in the diagnosis and treatment of renal diseases. Hemodialysis is the renal replacement modality in $70 \%$ of patients with ESRD [6].

Artreriovenous fistula is the favored form of dialysis access according to the guidelines on hemodialysis vascular access, and its dysfunction is a chief cause of morbidity and hospitalization in hemodialysis patients [6]. Well-timed intervention for retrieving early fistula failure is very important. However, clinically, it could take 3-4 months for nephrologists to confirm immature fistula. So, well-defined criteria applied in the early postoperative period after fistula creation for identification of fistulas that possible to fail would be very useful [7].

Blood flow increases rapidly after fistula creation and reaching its maximum within 4 to 12 weeks, about 40 to $60 \%$ of the total increase in blood flow occurs in the 1 st $24 \mathrm{~h}$ after creation of the fistula [7]. In this study, we measured blood flow at the fistula site in the early postoperative period (day 7-14) to assess if that has a predictive value in fistula failure by follow-up of the fistula maturity up to 6 months.

Our data revealed that age shows significant difference between the two groups (mature and failure group), but BMI shows no difference. However, Wiese et al. [8] reviewed that age and BMI show significant difference.

In agreement with previous studies, Sedlacek et al. [9] and Miller et al [10], our study revealed that DM is a risk factor for AV fistula failure. However, female sex was not a risk factor in our study as these studies reported. 


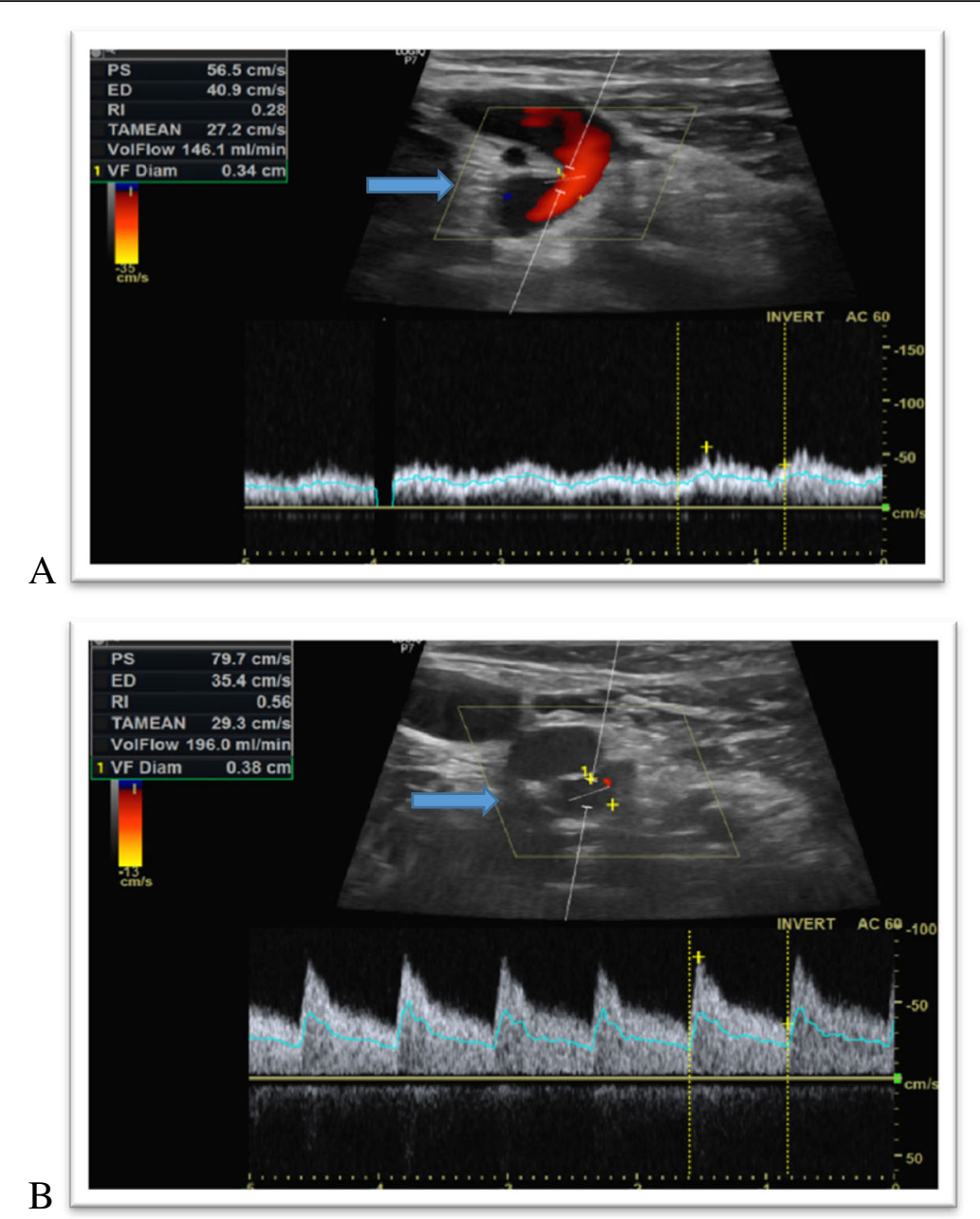

Fig. 4 A 41-year-old male patient with history of polycystic kidney. a Color Doppler US 10 days after the surgery demonstrates the blood flow at the anastomosis (volume flow is $146.1 \mathrm{ml} / \mathrm{min}$ ). b Color Doppler US demonstrates late postoperative period volume flow measurement $196 \mathrm{ml} /$ min, and this fistula failed to mature

Awareness of the primary renal disease helps the clinicians to expect problems during renal replacement therapy (RRT) and plan preventive measures for the community. In agreement with other studies, Zhu et al. [7] and Malekmakan et al. [1], our study detected that the most common causes of ESRD are chronic nephritis and diabetic nephropathy ( $47 \%$ and $24 \%$ respectively).

Table 5 Relation between outcome of fistula and type of anastomosis

\begin{tabular}{|c|c|c|c|c|c|c|}
\hline \multirow{3}{*}{$\begin{array}{l}\text { Studied } \\
\text { variables }\end{array}$} & \multicolumn{4}{|c|}{ Outcome of fistula } & \multirow{3}{*}{$\begin{array}{l}\text { Fisher's } \\
\text { exact } \\
\text { test }\end{array}$} & \multirow[t]{3}{*}{$P$ value } \\
\hline & \multicolumn{2}{|c|}{ Mature $(N=82)$} & \multicolumn{2}{|c|}{ Failed $(N=18)$} & & \\
\hline & No. & $\%$ & No. & $\%$ & & \\
\hline \multicolumn{7}{|c|}{ Type of anastomosis } \\
\hline End to end & 17 & 20.7 & 5 & 27.8 & 0.430 & 0.513 \\
\hline End to side & 65 & 79.3 & 13 & 72.2 & & \\
\hline
\end{tabular}

Preoperative vascular mapping was done to identify its predictive role in fistula failure, in agreement with previous studies, Zhu Y et al. [7] and Niyyar VD et al. [11], we reported that in addition to the diameters of cephalic vein, radial artery, and brachial artery, the peak systolic velocity of the radial artery and brachial artery was significantly lower in the failure group than in the mature group in our study, which indicated that the PSV and the vascular diameter are associated with the AV fistula failure.

Eighty-three percent of patients have their AV fistula by end to side technique and $17 \%$ by end to end technique. We noticed that there was no significant relation between outcome of the fistula and type of anastomosis. $20.7 \%$ of the mature group were end to end type, and $79.3 \%$ were end to side; $27.8 \%$ of the failure group were end to end, and $72.2 \%$ were end to side.

Failure group shows a significant decrease in blood flow at the early postoperative period (day7-14) compared to 
A

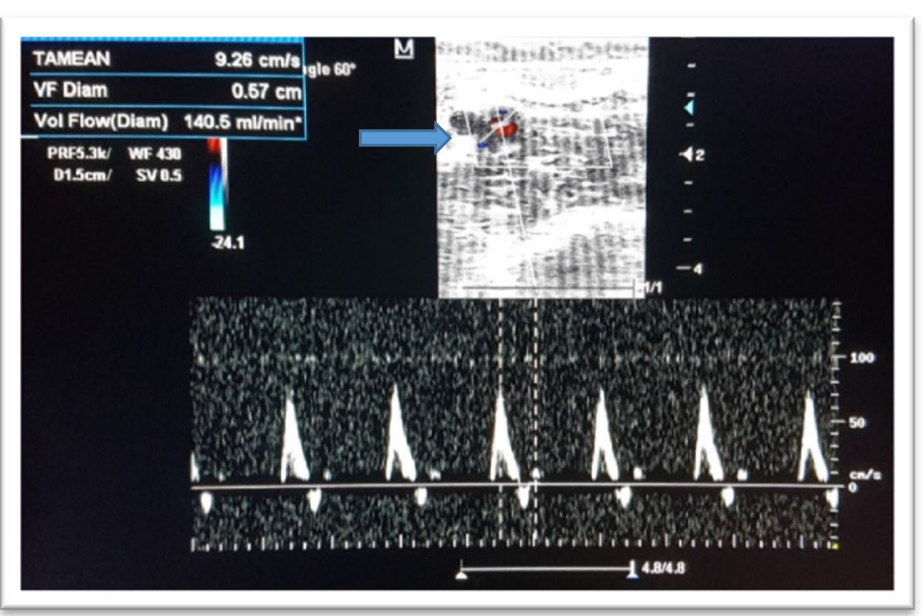

A

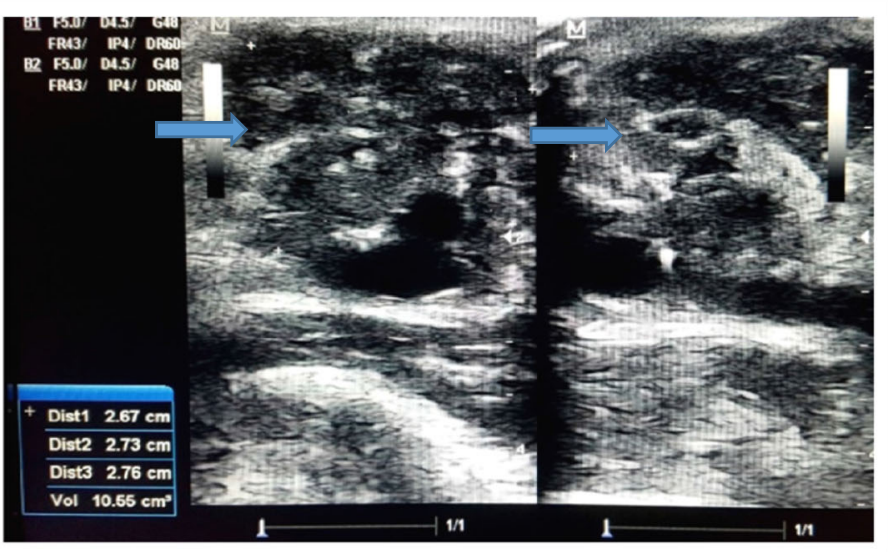

$\mathrm{B}$
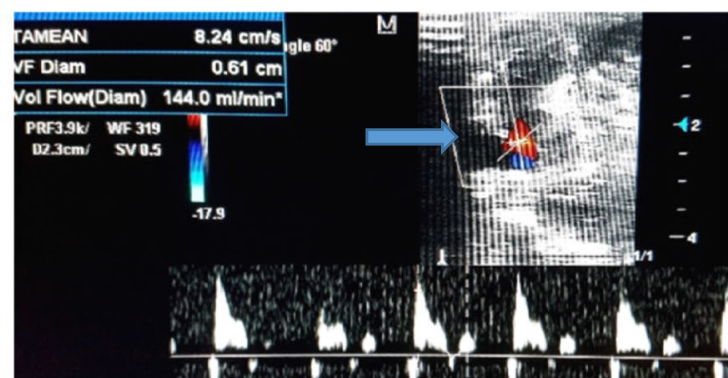

$-4$
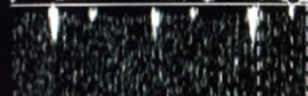

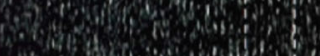

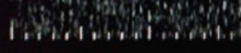

C

Fig. 5 A 57-year-old male patient with history of hypertensive nephropathy. a Color Doppler US 8 days after the surgery shows blood flow at the anastomosis (volume flow is $140 \mathrm{ml} / \mathrm{min}$ ). $\mathbf{b}$ B mode US demonstrates hematoma related to the AV fistula at the late postoperative period, and it measures $(2.6 \times 2.7 \times 2.7 \mathrm{~cm})$. c Color Doppler US shows the late postoperative period volume flow measurement $144 \mathrm{ml} / \mathrm{min}$, this fistula failed, and the cause of failure was hematoma

the mature group, which indicated that blood flow measurement at the early postoperative period could be used to differentiate the fistulas that were likely to fail and the ones that would ultimately mature. We detected that
$200.5 \mathrm{ml} / \mathrm{min}$ is the cutoff value for discriminating functioning and non-functioning fistulas. Ladenheim et al. [12] found that $200 \mathrm{ml} / \mathrm{min}$ blood flow in the postoperative 1st week is indicator of mature fistula. 
Table 6 Relation between outcome of fistula and postoperative ultrasound finding

\begin{tabular}{|c|c|c|c|c|}
\hline \multirow[t]{2}{*}{ Studied variables } & \multicolumn{2}{|c|}{ Outcome of fistula } & \multirow{2}{*}{$\begin{array}{l}\text { Mann- } \\
\text { Whitney } \\
\text { test }\end{array}$} & \multirow[t]{2}{*}{$P$ value } \\
\hline & $\begin{array}{l}\text { Mature } \\
(N=82)\end{array}$ & $\begin{array}{l}\text { Failed } \\
(n=18)\end{array}$ & & \\
\hline \multicolumn{5}{|c|}{$\begin{array}{l}\text { Early postoperative blood } \\
\text { flow }(\mathrm{ml} / \mathrm{min})\end{array}$} \\
\hline Mean \pm SD & $225.0 \pm 10.5$ & $196.7 \pm 11.3$ & 6.00 & $0.001^{* *}$ \\
\hline Median & 225.0 & 195.0 & & \\
\hline Range & $200-244$ & $183.0-234.0$ & & \\
\hline \multicolumn{5}{|c|}{$\begin{array}{l}\text { Late postoperative blood } \\
\text { flow (ml / } \mathrm{min})\end{array}$} \\
\hline Mean \pm SD & $567.1 \pm 142.0$ & $271.2 \pm 28.8$ & 6.62 & $0.001^{* *}$ \\
\hline Median & 559.5 & 271.0 & & \\
\hline Range & $375.0-934.0$ & $212.0-312.0$ & & \\
\hline $\begin{array}{l}\text { Percent of increase in } \\
\text { blood flow }\end{array}$ & $88 \%$ & $38.2 \%$ & & \\
\hline
\end{tabular}

A mature AV fistula in our study was one that could support pump-controlled blood flow of $377 \mathrm{~mL} / \mathrm{min}$ for 3 dialysis sessions at least.

Robbin et al. [13] considered an arteriovenous fistula mature when it could support blood flow of 350-450 $\mathrm{mL} / \mathrm{min}$, for 3-4 h three times per week. A fistula blood flow less than $350 \mathrm{~mL} / \mathrm{min}$ results in inadequate dialysis.

However, Zhu et al. [7] perceived in their study that blood flow have to be more than $200 \mathrm{~mL} / \mathrm{min}$ for at least 6 dialysis sessions in Chinese patients, probably because the body type and dietary structure of Chinese people.

In the follow-up period, $18 \%$ of arteriovenous fistulas (18 of 100) developed failure in our study.

Early AV fistula failure and insufficient flow rate are the most common problem [14]. Primary failure occurs if an access is unable to provide adequate blood flow for dialysis after reasonable period of maturation. It mostly occurs because the draining vein does not adequately dilates or the feeding artery does not provide sufficient blood flow [1].

Our study agrees with that as the most common cause of failure was failure to mature, and it represented $50 \%$ of failure group ( 9 patients), followed by hematoma (4 patients), followed by partial thrombosis ( 3 patients), and followed by total thrombosis and infection (1 patients each).

\section{Limitations}

We are aware that our study had limitations.

Table 7 Sensitivity and specificity of fistula blood flow measured by sonography in early postoperative period in detection of arteriovenous fistula failure among studied group

\begin{tabular}{lllllll}
\hline AUC & $\begin{array}{l}\text { Cutoff } \\
\text { point }\end{array}$ & $\begin{array}{l}\text { Sensitivity } \\
(\%)\end{array}$ & $\begin{array}{l}\text { Specificity } \\
(\%)\end{array}$ & $\begin{array}{l}\text { PPV } \\
(\%)\end{array}$ & $\begin{array}{l}\text { NPV } \\
(\%)\end{array}$ & $\begin{array}{l}\text { Accuracy } \\
(\%)\end{array}$ \\
\hline 0.952 & 200.5 & $99 \%$ & $89 \%$ & $98 \%$ & $94 \%$ & $97 \%$ \\
\hline
\end{tabular}

PPV positive predictive value, NPV negative predictive value
Table 8 Sensitivity and specificity of fistula blood flow measured by sonagraphy in late postoperative period in \begin{tabular}{lllll}
\multicolumn{4}{l}{ detection of arteriovenous fistula failure among studied group } \\
\hline AUC Cutoff Sensitivity Specificity PPV NPV Accuracy
\end{tabular}

\begin{tabular}{|c|c|c|c|c|c|c|}
\hline & point & (\%) & (\%) & (\%) & (\%) & $(\%)$ \\
\hline 1.00 & 377 & $99 \%$ & $100 \%$ & $100 \%$ & $95 \%$ & $99 \%$ \\
\hline
\end{tabular}

PPV positive predictive value, NPV negative predictive value

The arteriovenous fistulas in our study were made with end to side or end to end anastomoses, further studies regarding different types of anastomoses are needed.

Our study included small number of patients and short period of follow-up.

Intraoperative CDU assessment of arteriovenous fistula would be more helpful for prediction of maturity, and this was unavailable in our hospital.

\section{Conclusion}

Arteriovenous fistula blood flow measured by CDU during early postoperative periods may be a valuable and reasonably steady parameter for predicting failure of the fistula. Fistula blood flow of less than $200.5 \mathrm{~mL} / \mathrm{min}$ at day 7-14 after fistula construction may indicate a risk.

\section{Abbreviations}

AVF: Arteriovenous fistula; CDU: Color Doppler ultrasonography; ESRD: End stage renal disease; US: Ultrasound; PSV: Peak systolic velocity; VF: Volume flow; SV: Sample volume; TAV: Time average velocity; DM: Diabetes mellitus; BMI: Body mass index; CRF: Chronic renal failure; RRT: Renal replacement therapy

\section{Acknowledgements \\ There are no acknowledgements.}

\section{Authors' contributions}

MK, BF, and MR contributed equally to study design, data collection, analysis, and interpretation of results. All authors read and approved the final manuscript.

\section{Funding}

There is no funding.

Availability of data and materials

Data will be available upon request via contacting the corresponding author.

Ethics approval and consent to participate

All study procedures were conducted in accordance with the Decleration of Helsinki and were approved by the ethical committee of menoufia faculty of medicine, and all data were extracted after taking written informed consent from patients involved in study.

Committee's reference number 984/8/4/2018

Consent for publication

Written informed consent to publish the data was taken from the patients involved in this study.

\section{Competing interests}

The authors declare that they have no competing interests.

\section{Author details}

${ }^{1}$ Department of Radiodiagnosis, Faculty of Medicine, Menoufia University, Shibin Al Kawm, Egypt. ²Department of Radiodiagnosis, Shebin Elkom Teaching Hospital, Shibin Al Kawm, Menoufia, Egypt. 
Received: 21 January 2020 Accepted: 15 April 2020

Published online: 10 June 2020

\section{References}

1. Malekmakan L, Haghpanah S, Pakfetrat M et al (2009) Causes of chronic renal failure among Iranian hemodialysis patients. Saudi J Kidney Dis Transpl. 20(3):501-504

2. Shaheen AMFA, Al-Khader A (2005) Epidemiology and causes of end stage renal disease (ESRD). Saudi J Kidney Dis Transplant. 16(3):277-281

3. Malovrh M (2005) Native arteriovenous fistula: preoperative evaluation. Am J Kidney Dis. 39:1218-1225

4. Yerdel MA, Kesenci M, Yazicioglu KM et al (1997) Effect of hemodynamic variables on surgically created arteriovenous fistula flow. Nephrol Dial Transplant. 12(8):1684-1688

5. Wilmink T, Hollingworth L, Powers $S$ et al (2016) Natural history of common autologous arteriovenous fistulae: consequences for planning of dialysis access. Eur J Vasc Endovasc Surg. 51:134-140

6. Lee T (2013) Novel paradigms for dialysis vascular access: downstream vascular biology-is there a final common pathway? Clin J Am Soc Nephrol. 8:2194-2201

7. Zhu Y, Ding H, Fan P et al (2016) Is brachial artery blood flow measured by sonography during early postoperative periods predictive of arteriovenous fistula failure in hemodialysis patients? J Ultrasound Med. 35:1985-1992

8. Wiese P, Nonnast-Daniel B (2004) Colour Doppler ultrasound in dialysis access. Nephrol Dial Transplant. 19:1956-1963

9. Sedlacek M, Teodorescu V, Falk A et al (2001) Hemodialysis access placement with preoperative noninvasive vascular mapping: comparison between patients with and without diabetes. Am J Kidney Dis. 38:560-564

10. Miller CD, Robbin ML, Allon M (2003) Gender differences in outcomes of arteriovenous fistulas in hemodialysis patients. Kidney Int. 63:346-352

11. Niyyar VD, Wasse H (2009) Vascular mapping: does it help to maximize fistulae placement? Adv Chronic Kidney Dis 16(5):316-320

12. Ladenheim ED (2016) lulic D, lumm C, et al. first-week postoperative flow measurments are highly predictive of primary patency of radiocephalic arteriovenous fistulas. J vasc access. 17(4):307-312

13. Robbin ML, Chamberlain NE, Lockhart ME et al (2002) Hemodialysis arteriovenous fistula maturity: US evaluation. Radiology. 225:59-64

14. Hill SL, Donate AT (1991) Complication of dialysis access; a sex-year study. Am J Surg. 162:265-267

\section{Publisher's Note}

Springer Nature remains neutral with regard to jurisdictional claims in published maps and institutional affiliations.

\section{Submit your manuscript to a SpringerOpen ${ }^{\odot}$ journal and benefit from:}

- Convenient online submission

- Rigorous peer review

- Open access: articles freely available online

- High visibility within the field

- Retaining the copyright to your article

Submit your next manuscript at $\boldsymbol{\nabla}$ springeropen.com 